\title{
Aging and Respiratory Diseases
}

\author{
Shahrukh Arif ${ }^{1,2}$ and Margaret A Pisani² \\ 1. Northeast Medical Group, Yale-New Haven Hospital, New Haven, CT, USA; 2. Yale University School of Medicine, New Haven, CT, USA
}

DOI: https://doi.org/10.17925/USPRD.2020.5.1.33

\begin{abstract}
A ging is associated with multiple structural changes in the respiratory system, resulting in increased susceptibility to disease processes. Symptoms including cough and dyspnea are common in the elderly and require a stepwise approach for diagnosis of underlying conditions. Older patients are often misdiagnosed and inappropriately treated for respiratory diseases. This article aims to discuss the challenges associated with the diagnosis and management of common respiratory conditions in elderly patients.
\end{abstract}

\section{Keywords}

Aging, elderly, asthma, COPD, lung cancer

Disclosures: Shahrukh Arif and Margaret A Pisani have no financial or non-financial relationships or activities to declare in relation to this article.

Review Process: Double-blind peer review.

Compliance with Ethics: This article involves a review of the literature and did not involve any studies with human or animal subjects performed by any of the authors.

Authorship: The named authors meet the International Committee of Medical Journal Editors (ICMJE) criteria for authorship of this manuscript, take responsibility for the integrity of the work as a whole, and have given final approval for the version to be published.

Access: This article is freely accessible at touchRESPIRATORY.com (c) Touch Medical Media 2020.

Received: March 18, 2020

Accepted: September 4, 2020

Published Online: December 23, 2020

Citation: US Respiratory \& Pulmonary Diseases. 2020;5(1): 33-7

Corresponding Author: Margaret A Pisani,

Yale University School of Medicine, New Haven, CT 06510,

USA. E: margaret.pisani@yale.edu Twitter: @PisaniMAP

Support: No funding was received in

the publication of this article.
As our ability to treat and manage chronic medical conditions improves, we will see a greater number of our patients manifesting physiologic as well as pathologic changes associated with aging. The objective of this article is to provide a brief overview of physiologic changes seen in the respiratory system with aging, and to discuss commonly encountered challenges associated with the management of pulmonary disorders in the elderly patient population. PubMed was searched, using the keywords "aging" and "elderly", combined with "asthma", "COPD", and "lung cancer". The references of appropriate papers were then reviewed to obtain further relevant information.

Aging is a complex biologic process that is characterized by irreversible functional and anatomic changes in the body, resulting in increased susceptibility to disease processes. The respiratory system undergoes multiple changes with aging, which increases the frequency of commonly seen symptoms, such as cough, rhinitis, and dyspnea. As people age, nasal passages become less cartilaginous resulting in overall decreased patency. Similar changes in the collagen support network occur at the level of proximal and distal airways, which causes enlargement of alveolar ducts leading to air trapping and loss of surface area for gas exchange. The efficiency of gas exchange is further affected by a decrease in the diffusing capacity of carbon monoxide at an approximate rate of $5 \%$ per decade. ${ }^{2}$ There is a loss in contractility of intercoastal and diaphragmatic muscles, resulting in overall decreased expansion of airways and increased atelectasis. ${ }^{3}$ Due to decreased chest wall muscle strength, the cough becomes less effective. There is also a decrease in the effectiveness of mucociliary clearance with age. ${ }^{4}$ The rate at which these changes occur is influenced by genetic predisposition as well as environmental factors, like cigarette smoking. The decrease in the elastic recoil and compliance seen in older patients contributes to a diminished respiratory reserve, which then contributes to acute conditions, such as pulmonary edema, pneumonia, and bronchospasm. ${ }^{5}$ Clinicians should keep these physiologic changes in mind while evaluating older adults presenting with pulmonary-related symptoms and consider them in diagnosis and management.

\section{Evaluation of commonly reported respiratory symptoms in the elderly}

The most commonly reported pulmonary symptoms in the elderly include dyspnea, cough, and decreased exercise tolerance. These symptoms can be caused by a variety of pulmonary, as well as non-pulmonary, conditions. Cough with sputum is reported by up to $27 \%$ of elderly patients and is associated with increased mortality. ${ }^{6}$ Similarly, dyspnea is highly prevalent in the elderly, and is reported by approximately $30 \%$ of individuals $>65$ years of age. ${ }^{7}$ Due to the high likelihood of multiple comorbid conditions, all elderly patients presenting with symptoms of dyspnea and cough should be approached with a broad differential in mind.

Acute onset of dyspnea in the elderly, especially when associated with changes in vital signs (tachycardia, tachypnea, or fever), is best evaluated in the emergency room. Chronic dyspnea requires a stepwise approach to diagnose the underlying condition. After obtaining a thorough history and physical examination, a chest $\mathrm{x}$-ray should always be considered as the first diagnostic tool. 
Table 1: Two phenotypes of asthma

\begin{tabular}{|l|l|l|}
\hline & Late-onset & Long-standing asthma \\
\hline Age of onset & Variable but typically as an adult & $<12$ years of age \\
\hline FEV1 & Higher & Lower \\
\hline TH2-mediated disease & Less commonly & More commonly \\
\hline Family history & $(-)$ & $(+)$ \\
\hline Association with atopy & $(-)$ & $(+)$ \\
\hline Association with obesity & $(+)$ & $(-)$ \\
\hline Association with tobacco use & $(+)$ & $(-)$ \\
\hline
\end{tabular}

FEV1 = forced expiratory volume in 1 second; $\mathrm{TH} 2$ = type 2 helper $\mathrm{T}$ cells. Adapted with permission from Dunn et al. 2017. ${ }^{15}$

Chest $x$-rays are readily available, cost effective, and can provide valuable information in a variety of pulmonary conditions. Infiltrates may point towards pneumonia; findings of edema are suggestive of heart failure; prominent interstitial markings can be seen in interstitial lung disease; and hyperinflation suggests chronic obstructive pulmonary disease (COPD). However, further evaluation with pulmonary function testing, echocardiogram, and chest computed tomography (CT) scan is often needed for a complete evaluation of chronic dyspnea.

\section{Asthma}

Asthma is a chronic inflammatory condition characterized by reversible airway obstruction resulting in recurring and variable symptoms of cough, wheeze, shortness of breath, and chest tightness. Asthma remains a highly prevalent and deadly disease in patients $>65$ years old. The prevalence of self-reported asthma in this age group is $6.8 \%$ and the lifetime prevalence is estimated to be $13 \% .8,9$ Compared with younger patients, asthma in older patients is associated with higher mortality, more severe exacerbations, and longer hospital stays. ${ }^{10}$ These trends can be explained by increased burden of comorbid conditions, higher rates of misdiagnosis and underdiagnosis, ${ }^{11}$ decreased perception of asthma-related symptoms, ${ }^{12,13}$ and underutilization of guideline-directed management. ${ }^{14}$ The two distinct types of asthma phenotypes described in older patients include late-onset and longstanding (Table 1). Late-onset asthma usually presents in middle age, is less commonly associated with atopy and positive family history, and is more frequently associated with tobacco use and obesity. ${ }^{15}$

Asthma should be suspected in patients presenting with symptoms of bronchoconstriction, including cough, shortness of breath, wheeze, and chest tightness. Frequently, symptoms are subtle and easily misdiagnosed or overlooked. Diagnosis of asthma in older patients requires a careful approach that is centered around ruling out other causes of dyspnea and wheezing, including COPD, bronchiectasis, constrictive bronchiolitis, and congestive heart failure. In one study, it was reported that asthma in older patients can be misdiagnosed as COPD in up to 20\% cases. ${ }^{11}$ Compared with COPD, asthma in older patients is more likely to have increased serum and sputum eosinophils, greater bronchodilator response, and association with atopic conditions, while the presence of hypoxemia, heavy smoking history, and hyperinflation of lungs points towards COPD. ${ }^{16,17}$

Despite these well-defined differences, the diagnosis of asthma remains a challenging issue. An improvement in forced expiratory volume in 1 second
(FEV1) of at least $12 \%$ after receiving short-acting bronchodilator is helpful in establishing a diagnosis, but this can also be present in COPD. While interpreting the results of spirometry in the elderly, it is essential to use age-adjusted values due to an accelerated decline in FEV1 as a result of aging. ${ }^{18,19}$ Frailty and cognitive impairment in the elderly can increase the challenges of obtaining accurate results using spirometry. ${ }^{20-22}$ Provocation testing using methacholine can be used in older patients with normal baseline spirometry; however, it should be noted that there is conflicting evidence regarding increased airway hyperresponsiveness due to aging itself, which may lead to false-positive results. ${ }^{23-25}$ Based on a study by Columbo and colleagues, there was no correlation between exhaled nitrous oxide and spirometric values. ${ }^{26}$ However, more recent literature showed a correlation of fraction of exhaled nitrous oxide with asthma symptoms and a previous diagnosis of asthma. ${ }^{27}$ The utility of measuring the fraction of exhaled nitrous oxide in older patients with asthma remains unclear and requires further research.

There are no age-specific guidelines for the treatment of asthma. The goal of asthma management is to control symptoms, prevent acute exacerbation, and reduce the need for hospitalization. Treatment of asthma in older individuals should be tailored using established guidelines. ${ }^{28}$ Common classes of medications and their side-effect profiles are listed in Table 2. Inhaled corticosteroids are an important component of asthma management, but they are significantly underutilized in older adults. ${ }^{14}$ Older patients with asthma are at higher risk of treatment failure compared with young patients. ${ }^{29}$ There are multiple challenges associated with the treatment of asthma in older patients including the decreased perception of asthma symptoms, ${ }^{12,13}$ lower adherence to medications due to cognitive impairment, ${ }^{30}$ poor inhaler techniques, ${ }^{31}$ and higher risks of side effects. ${ }^{32,33}$

\section{Chronic obstructive pulmonary disease}

COPD is defined by the Global Initiative for Chronic Obstructive Lung Disease (GOLD) as "A common, preventable, and treatable disease that is characterized by persistent respiratory symptoms and airflow limitation that is due to airway and/or alveolar abnormalities usually caused by significant exposure to noxious particles or gases. ${ }^{\text {" }} 4$ It is reported to be the fourth leading cause of mortality in the USA, ${ }^{35}$ and is associated with aging, ${ }^{36}$ inhalational exposure to tobacco smoke, occupational dust and chemicals, and air pollution. ${ }^{37}$ There is a high burden of comorbid conditions in older patients with COPD, which creates multiple diagnostic and management challenges. ${ }^{38-40}$ Older patients with COPD may attribute their 
Table 2: Medications used in the management of asthma

\begin{tabular}{|c|c|}
\hline $\begin{array}{l}\text { LAMAS } \\
\text { Add on to ICSS and LABAS; } \\
\text { More useful in COPD and COPD/asthma overlap syndrome }\end{array}$ & $\begin{array}{l}\text { Overall, well tolerated, and no data to suggest significant systemic } \\
\text { antimuscarinic effects }\end{array}$ \\
\hline $\begin{array}{l}\text { Short-acting beta-adrenergic agonists } \\
\text { Used as a rescue inhaler }\end{array}$ & Tachycardia, tremors, and hypokalemia \\
\hline $\begin{array}{l}\text { Leukotriene receptor antagonists } \\
\text { Used as maintenance therapy }\end{array}$ & Overall, well tolerated \\
\hline
\end{tabular}

COPD = chronic obstructive pulmonary disease; ICS = inhaled corticosteroid; IgE = immunog/obulin E; LABA = Iong-acting beta-adrenergic agonist;

LAMA = long-acting muscarinic antagonist.

symptoms of COPD to comorbid conditions like congestive heart failure, muscle weakness, physical deconditioning, or age-related changes..$^{35}$ When evaluating older patients with COPD, it is important to know that these patients may use different wording to describe dyspnea like "awful," "terrifying," or "frightening" as opposed to patients without COPD. ${ }^{41}$

As discussed above, there are several age-related, unavoidable structural changes in the lung that lead to a decrease in lung functions. This creates an issue of overdiagnosis of COPD in older patients. ${ }^{42,43}$ It was found that up to $35 \%$ of healthy and asymptomatic patients aged $\geq 70$ can be diagnosed as COPD stage I based on GOLD definitions. ${ }^{42}$ In order to reduce the risk of overdiagnosis of COPD in older patients, the American Thoracic Society and European Respiratory Society recommend using less than the fifth percentile of the normal distribution of FEV1 and vital capacity ratio as the cutoff for diagnosing of COPD. ${ }^{44}$ There are no age-specific guidelines for COPD in older patients, and management should be guided using the most recently published GOLD guidelines. ${ }^{34}$ In addition to inhaler therapies, long-term oxygen use, smoking cessation, and pulmonary rehabilitation are integral components of management. Common medications used to treat COPD are listed in Table 3. Inappropriate inhaler techniques, non-adherence to medications, and increased risk of medication-related side effects are common challenges with the treatment of COPD in older patients. ${ }^{45}$

There are positive outcomes associated with the use of long-acting inhaled bronchodilators in COPD including reduced symptoms, ${ }^{46}$ fewer acute exacerbations, and improvement in spirometric values. ${ }^{47}$ Inhaled corticosteroids, when used in combination with inhaled bronchodilator therapy, are associated with a decrease in emergency visits, need for hospitalization, and intubation..$^{48-51}$ Non-pharmacologic interventions, such as smoking cessation, oxygen therapy in patients with resting hypoxia, and pulmonary rehabilitation are associated with improved survival and quality of life in patients with COPD. . $2,53^{2}$

\section{Lung cancer}

Lung cancer is a common malignancy and one of the leading causes of cancer-related deaths in the USA. It is diagnosed in approximately 230,000 patients and results in 135,000 deaths annually. Despite the improvement in mortality in recent years, lung cancer has caused more deaths than colorectal, prostate, breast, and brain cancer combined.54 Its incidence increases with age and peaks between the ages of 59 and 75 years. ${ }^{55,56}$ Cigarette smoking is the number one risk factor for lung cancer and is associated with up to $90 \%$ of lung cancer cases. ${ }^{57}$ This risk is significantly reduced with the cessation of cigarette smoking with the greatest reduction in risk when cigarette smoking is stopped prior to age 30 years. ${ }^{58}$ Cigar and pipe smoking are also associated with an increased incidence of lung cancer, but the risk is substantially less than cigarette smoking. ${ }^{57}$ Other risk factors for the development of lung cancer include radiation therapy; ${ }^{59}$ history of pulmonary fibrosis; $; 0$ human immunodeficiency virus (HIV) infection; ${ }^{61}$ and exposure to secondhand smoke, radon, asbestos, arsenic, nickel, chromium, and polycyclic aromatic hydrocarbons. ${ }^{57}$

The majority of lung cancers are advanced at the time of diagnosis and it is common for patients to have metastatic disease at the time of presentation. ${ }^{62}$ The most common symptoms of lung cancer are cough, weight loss, and dyspnea. Other less common symptoms include chest pain, hemoptysis, bone pain, and hoarseness. ${ }^{63}$ Most cases of lung cancer can be broadly categorized into non-small cell lung cancer (NSCLC) and small cell lung cancer (SCLC), based on histologic subtype. These drive the decisions regarding management and prognosis. The treatment of lung cancer should not be solely based on the patient's age, but it is important to take age-related changes in functional status and cognition into account when formulating a management plan. There are data that demonstrate that older patients treated with surgical resection for lung cancer had comparable outcomes to younger patients.64,65 Despite this, older patients are less likely to receive appropriate therapy compared with young patients. ${ }^{66}$ 
Table 3: Medications used in the management of chronic obstructive pulmonary disease

\begin{tabular}{|c|c|}
\hline Classes and names of medications & Side effects \\
\hline $\begin{array}{l}\text { LAMAS } \\
\text { Tiotropium, umeclidinium, glycopyrronium bromide, and aclidinium bromide }\end{array}$ & Overall, well tolerated \\
\hline $\begin{array}{l}\text { Multidrug combinations } \\
\text { SABA/SAMA: albuterol//pratropium } \\
\text { LABA/LAMA: vilanterol/umeclidinium, formoterol/glycopyrronium }\end{array}$ & $\begin{array}{l}\text { Tachycardia, tremors, dry mouth, blurring of vision, urinary retention, constipation, } \\
\text { and hypokalemia }\end{array}$ \\
\hline $\begin{array}{l}\text { ICSS } \\
\text { Budesonide, fluticasone, mometasone, and beclometasone. } \\
\text { Used as a LABA/ICS or LABA/LAMA/ICS combination }\end{array}$ & Associated with adrenal insufficiency and increased risk of parasitic infections \\
\hline $\begin{array}{l}\text { Methylxanthines } \\
\text { Aminophylline and theophylline }\end{array}$ & $\begin{array}{l}\text { Lower seizure threshold, arrhythmias, electrolyte disturbances, headache, and } \\
\text { drug-drug interactions }\end{array}$ \\
\hline $\begin{array}{l}\text { Phosphodiesterase-4 inhibitors } \\
\text { Roflumilast }\end{array}$ & Diarrhea, nausea, anorexia, insomnia, and headache \\
\hline
\end{tabular}

ICS = inhaled corticosteroid; $L A B A=$ long-acting beta-adrenergic agonist; LAMA = long-acting muscarinic antagonist; $S A B A=$ short-acting beta-adrenergic agonists; SAMA = short-acting muscarinic antagonists.

The treatment of lung cancer in older patients should be done in line with published guidelines of the American College of Chest Physicians. Surgical resection is usually the most suitable treatment option for patients with early NSCLC. Patients who are deemed nonsurgical candidates, or those with advanced disease, may be treated with radiation therapy, chemotherapy, and/or immunotherapy. Chemotherapeutic options are associated with a wide variety of short- and long-term toxicities in older patients, ${ }^{67}$ however, there are data suggesting that chemotherapy for NSCLC and SCLC have acceptable safety and outcome profiles in older patients. ${ }^{68,69}$

It is common for lung cancer patients to have advanced disease at the time of initial presentation, ${ }^{62}$ which leads to overall poor outcomes. Thus, in recent years, there has been intense research on the development of screening models for lung cancer. Several modalities for lung cancer screening have been investigated, including sputum cytology, chest radiograph, and low-dose CT scan. The National Lung Cancer Screening Trial (NLST) was a multicenter, randomized control trial that compared low-dose CT scan with chest radiograph in asymptomatic adults aged 55-74 with $>30$ pack-year smoking history. It included current as well as former smokers who quit within the past 15 years. NLST showed a significant reduction in mortality in patients who underwent low-dose chest CT for the detection of lung cancer. ${ }^{70}$ Sputum cytology and chest radiographs are not recommended for lung cancer screening. ${ }^{70-72}$ Based on the published data supporting the use of low-dose chest CT for lung cancer in the high-risk patient population, the United States Preventative Task Force implemented guidelines recommending annual screening for lung cancer with a low-dose
CT scan for adults aged 55-80 who have a 30 pack-year smoking history and currently smoke or have quit within the past 15 years. Screening is not recommended for patients with substantially limited life expectancy, contraindication, or unwillingness to undergo curative lung surgery.

\section{Conclusion}

Despite recent advances in the field of pulmonary medicine, there is still room for improvement in the diagnosis and management of common pulmonary diseases in the older patient population. When evaluating older patients, clinicians should be mindful of physiologic and anatomic changes associated with aging. The burden of coexisting medical conditions is frequently much higher in older patients and many of these comorbidities can mimic pulmonary disorders. The evidence suggests that pulmonary diseases are often misdiagnosed as well as inappropriately treated in elderly patients. Both asthma and COPD are common in the elderly and are associated with increased mortality. Diagnosis is often challenging due to coexisting medical conditions that may present with similar symptoms. In addition, changes in cognition and pulmonary physiology may limit the utility of commonly used testing tools, like pulmonary function testing. Similar to COPD, the incidence of lung cancer increases with age. It is often diagnosed late, and older patients are less likely to receive appropriate and timely management compared with younger patients. More research is needed to better identify these challenges and issues in the management of pulmonary disorders in elderly patients. It is also important to educate medical practitioners on this topic so that appropriate and evidenced-based patient care is provided to older patients. 
1. Gillooly M, Lamb D. Airspace size in lungs of lifelong non-smokers: effect of age and sex. Thorax. 1993;48:39-43.

2. Stam $\mathrm{H}$, Hrachovina V, Stijnen T, Versprille A. Diffusing capacity dependent on lung volume and age in normal subjects. J App/ Physiol (1985). 1994;76:2356-63.

3. Estenne $\mathrm{M}$, Yernault J, De Troyer A. Rib cage and diaphragm-abdomen compliance in humans: effects of age and posture. J Appl Physiol (1985) $1985 \cdot 59: 1842-8$

4. Ho J, Chan K, Hu W, et al. The effect of aging on nasal mucociliary clearance, beat frequency, and ultrastructure of respiratory cilia. Am J Respir Crit Care Med. 2001;163:983-8.

5. Janssens J. Aging of the respiratory system: impact on pulmonary function tests and adaptation to exertion. Clin Chest Med. 2005;26:469-84.

6. Hewitt J. Respiratory symptoms in older people and their association with mortality. Thorax. 2005;60:331-4.

7. Mahler D. Evaluation of dyspnea in the elderly. Clin Geriatr Med. 2017;33:503-21

8. Moorman JE, Rudd RA, Johnson CA, et al. National surveillance for asthma-United States, 1980-2004. MMWR Surveill Summ. 2007;56:1-54.

9. Parameswaran $\mathrm{K}$, Hildreth $\mathrm{AJ}$, Chadha $\mathrm{D}$, et al. Asthma in the elderly: underperceived, underdiagnosed and undertreated; a community survey. Respir Med. 1998;92:573-7.

10. Tsai C, Lee W, Hanania N, Camargo C. Age-related differences in clinical outcomes for acute asthma in the United States, 2006-2008. J Allergy Clin Immunol. 2012;129:1252-8.e1.

11. Bellia V, Battaglia S, Catalano F, et al. Aging and disability affect misdiagnosis of COPD in elderly asthmatics. Chest. 2003;123:1066-72.

12. Connolly MJ, Crowley JJ, Charan NB, et al. Reduced subjective awareness of bronchoconstriction provoked by methacholine in elderly asthmatic and normal subjects as measured on a simple awareness scale. Thorax. 1992;47:410-3

13. Joo J, Lim G, Seo M, et al. Perception of wheezing in the elderly asthmatics. Korean I Intern Med. 2001;16:260-4.

14. Hartert T, Togias A, Mellen B, et al. Underutilization of controller and rescue medications among older adults with asthma requiring hospital care J Am Geriatr SOC. 2000:48:651-7.

15. Dunn $R$, Busse P, Wechsler M. Asthma in the elderly and late-onset adult asthma. Allergy. 2017;73:284-94.

16. Sin BA, Akkoca O, Saryal S, et al. Differences between asthma and COPD in the elderly. I Investig Allergol Clin Immunol. 2006;16:44-50.

17. Di Lorenzo G, Mansueto P, Ditta V, et al. Similarity and differences in elderly patients with fixed airflow obstruction by asthma and by chronic obstructive pulmonary disease. Respir Med. 2008:102:232-8.

18. Quanjer P, Stanojevic S, Cole T, et al. Multi-ethnic reference values for spirometry for the 3-95-yr age range: the global lung function 2012 equations. Eur Respir J. 2012;40:1324-43.

19. Vaz Fragoso C, MCAvay G, Van Ness P, et al. Phenotype of normal spirometry in an aging population. Am J Respir Crit Care Med. 2015;192:817-25.

20. Allen S, Yeung P. Inability to draw intersecting pentagons as a predictor of unsatisfactory spirometry technique in elderly hospital inpatients. Age Ageing. 2006:35:304-6.

21. Allen SC, Ragab S. Ability to learn inhaler technique in relation to cognitive scores and tests of praxis in old age. Postgrad Med $\mathrm{J}$. 2002;78:37-9.

22. Bellia V, Pistelli R, Catalano F, et al. Quality control of spirometry in the elderly. The SA.R.A. study. SAlute Respiration nell'Anziano $=$ respiratory health in the elderly. Am J Respir Crit Care Med. 2000:161:1094-100

23. Scichilone N, Messina M, Battaglia S, et al. Airway hyperresponsiveness in the elderly: prevalence and clinica implications. Eur Respir J. 2005;25:364-75.

24. Renwick $D$, Connolly $M$. The relationship between age and bronchial responsiveness. Chest. 1999;115:660-5.

25. Cuttitta G, Cibella F, Bellia V, et al. Changes in FVC during methacholine-induced bronchoconstriction in elderly patients with asthma. Chest. 2001;119:1685-90.
26. Columbo M, Wong B, Panettieri R, Rohr A. Asthma in the elderly: the role of exhaled nitric oxide measurements. Respir Med. 2013;107:785-7.

27. Aarestrup F, Netto A, dos Reis T, et al. Fraction of exhaled nitric oxide measurements in the diagnoses of asthma in elderly patients. Clin Interv Aging. 2016:11:623-9.

28. Global Initiative for Asthma, GINA. Global Initiative for Asthma - GINA, 2016. Available at: http://ginasthma.org/ (accessed October 6, 2020)

29. Dunn R, Lehman E, Chinchilli V, et al. Impact of age and sex on response to asthma therapy. Am J Respir Crit Care Med. 2015;192:551-8.

30. Bozek A, Jarzab J. Adherence to asthma therapy in elderly patients. J Asthma. 2010;47:162-5.

31. Allen $S$, Jain $M$, Ragab $S$, Malik N. Acquisition and short-term retention of inhaler techniques require intact executive function in elderly subjects. Age Ageing. 2003;32:299-302.

32. Salpeter S, Ormiston T, Salpeter E. Cardiovascular effects of $\beta$-agonists in patients with asthma and COPD. Chest. 2004;125:2309-21.

33. Etminan M, Sadatsafavi M, Ganjizadeh Zavareh S, et al. Inhaled corticosteroids and the risk of fractures in older adults. Drug Safety. 2008;31:409-14.

34. Global Initiative for Chronic Obstructive Lung Disease (GOLD). Global strategy for the diagnosis, management and prevention of chronic obstructive pulmonary disease: 2019 report. Available at: https://goldcopd.org/ (accessed October 6, 2020).

35. Akgun K, Crothers K, Pisani M. Epidemiology and management of common pulmonary diseases in older persons. I Gerontol A Biol Sci Med Sci. 2012;67A:276-91.

36. Lindberg A, Eriksson B, Larsson L, et al. Seven-year cumulative incidence of COPD in an age-stratified general population sample. Chest. 2006;129:87985.

37. Pauwels R, Buist A, Jenkins $C R$, Hurd SS; GOLD Scientific Committee. Global strategy for the diagnosis, management, and prevention of chronic obstructive pulmonary disease. Am J Respir Crit Care Med. 2001;163:1256-76.

38. Barr R, Celli B, Mannino D, et al. Comorbidities, patient knowledge, and disease management in a national sample of patients with COPD. Am J Med. 2009:122:348-55.

39. Padeletti M, Jelic S, LeJemtel T. Coexistent chronic obstructive pulmonary disease and heart failure in the elderly. Int I Cardiol. 2008;125:209-15.

40. Yeo J, Karimova G, Bansal S. Co-morbidity in older patients with COPD -its impact on health service utilisation and quality of life, a community study. Age Ageing. 2006;35:33-7.

41. Williams $M$, Cafarella P, Olds T, et al. The language of breathlessness differentiates between patients with COPD and age-matched adults. Chest. 2008;134:489-96.

42. Hardie J, Buist A, Vollmer W, et al. Risk of over-diagnosis of COPD in asymptomatic elderly never-smokers. Eur Respir J. 2002;20:1117-22

43. Medbø A, Melbye H. Lung function testing in the elderly — can we still use FEV1/FVC $<70 \%$ as a criterion of COPD? Respir Med. 2007;101:1097-105

44. Pellegrino R, Viegi G, Brusasco V, et al. Interpretative strategies for lung function tests. Eur Respir J. 2005:26:948-68.

45. Corsonello A, Scarlata S, Pedone C, et al. Treating COPD in older and oldest old patients. Curr Pharm Des. 2015;21:1672-89.

46. Ramirez-Venegas A, Ward J, Lentine T, Mahler D. Salmeterol reduces dyspnea and improves lung function in patients with COPD. Chest. 1997;112:336-40.

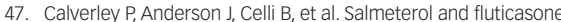
propionate and survival in chronic obstructive pulmonary disease. N Engl J Med. 2007;356:775-89.

48. Dalal AA, Petersen $\mathrm{H}$, Simoni-Wastila L, Blanchette CM. Healthcare costs associated with initial maintenance therapy with fluticasone propionate $250 \mu \mathrm{g} / \mathrm{salmeterol} 50 \mu \mathrm{g}$ combination versus anticholinergic bronchodilators in elderly US Medicare-eligible beneficiaries with COPD. J Med ECon. 2009;12:339-47.

49. Dalal AA, Shah M, D'Souza AO, Mapel DW. COPD-related healthcare utilization and costs after discharge from a hospitalization or emergency department visit on a regimen of fluticasone propionatesalmeterol combination versus other maintenance therapies. Am J Manag Care. 2011;17:e55-65.

50. Malo de MR, Mortensen EM, Restrepo MI, et al. Inhaled corticosteroid use is associated with lower mortality for subjects with COPD and hospitalised with pneumonia. Eur Respir 」. 2010;36:751-7.

51. Chen D, Restrepo MI, Fine MJ, et al. Observational study of inhaled corticosteroids on outcomes for COPD patients with pneumonia. Am J Respir Crit Care Med. 2011;184:312-6.

52. $\operatorname{Sin} \mathrm{D}, \mathrm{MCAlister} F$, Man $\mathrm{S}$, Anthonisen N. Contemporary management of chronic obstructive pulmonary disease: scientific review. JAMA. 2003:290:2301.

53. Man $\mathrm{S}, \mathrm{MCAlister} F$, Anthonisen $\mathrm{N}$, Sin D. Contemporary management of chronic obstructive pulmonary disease: clinical applications. JAMA. 2003;290:2313

54. Siegel R, Miller K, Jemal A. Cancer statistics, 2020. CA Cancer J Clin. 2020;70:7-30

55. O'Rourke MA, Feussner JR, Feigl P, Laszlo J. Age trends of lung cancer stage at diagnosis. JAMA. 1987;258:921-6.

56. SEER Cancer Statistics Review (CSR) 1975-2008, 2011. Available at: https://seer.cancer.gov/archive/csr/1975_2008/ (accessed October 7, 2020).

57. Alberg A, Samet J. Epidemiology of Lung Cancer. Chest. 2003;123:21-49S.

58. Doll R, Peto R, Boreham J, Sutherland I. Mortality in relation to smoking: 50 years' observations on male British doctors. BMJ. 2004;328:1519.

59. Lorigan P, Radford J, Howell A, Thatcher N. Lung cancer after treatment for Hodgkin's lymphoma: a systematic review. Lancet Oncol. 2005;6:773-9.

60. Hubbard R, Venn A, Lewis S, et al. Lung cancer and cryptogenic fibrosing alveolitis. A population-based cohort study. Am J Respir Crit Care Med. 2000;161:5-8

61. Kirk G, Merlo $C, O^{\prime}$ Driscoll P, et al. HIV infection is associated with an increased risk for lung cancer, independent of smoking. Clin Infect Dis. 2007;45:103-10.

62. Cetin K, Ettinger D, Hei, O'Malley C. Survival by histologic subtype in stage IV nonsmall cell lung cancer based on data from the Surveillance, Epidemiology and End Results Program. Clin Epidemiol. 2011;3:139-48.

63. Hyde L, Hyde C. Clinical manifestations of lung cancer. Chest. 1974;65:299-306.

64. O'Rourke M, Crawford J. Lung cancer in the elderly. Clin Geriatr Med. 1987;3:595-623.

65. Coate L, Massey C, Hope A, et al. Treatment of the elderly when cure is the goal: the influence of age on treatment selection and efficacy for stage III non-small cell lung cancer. J Thorac Oncol. 2011:6:537-44.

66. Guadagnoli E, Weitberg A, Mor V, et al. The influence of patient age on the diagnosis and treatment of lung and colorectal cancer. Arch Intern Med. 1990;150:1485-90.

67. Hardy D, Cormier J, Xing Y, et al. Chemotherapy-associated toxicity in a large cohort of elderly patients with non-small cell lung cancer. J Thorac Oncol. 2010:5:90-8.

68. Igawa S, Ryuge S, Fukui T, et al. Amrubicin for treating elderly and poor-risk patients with small-cell lung cancer. Int J Clin Oncol. 2010;15:447-52.

69. Leighl N, Zatloukal P, Mezger J, et al. Efficacy and safety of bevacizumab-based therapy in elderly patients with advanced or recurrent nonsquamous non-small cell lung cancer in the phase III B017704 study (AVAiL). J Thorac Oncol. 2010;5:1970-6.

70. Aberle DR, Adams AM, Berg CD, et al. Reduced lung-cancer mortality with low-dose computed tomographic screening. N Engl J Med. 2011;365:395-409.

71. Manser $R$, Lethaby $A$, Irving $L B$, et al. Screening for lung cancer. Cochrane Database Syst Rev. 2013;2013:CD001991.

72. Prorok P, Andriole G, Bresalier R, et al. Design of the prostate, lung colorectal and ovarian (PLCO) cancer screening trial. Control Clin Trials. 2000;21:273-309S. 